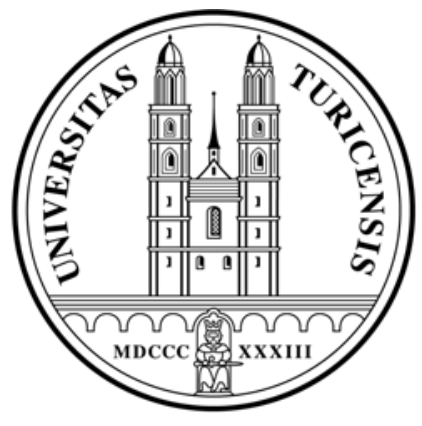

Institute for Empirical Research in Economics

University of Zurich

Working Paper Series

ISSN 1424-0459

Working Paper No. 465

\title{
Precautionary Corporate Liquidity
}

Kaiji Chen, Zheng Song and Yikai Wang

January 2010 


\title{
Precautionary Corporate Liquidity*
}

\author{
Kaiji Chen ${ }^{\dagger}$ \\ University of Oslo
}

\author{
Zheng Song $\ddagger$ \\ Fudan University
}

\author{
Yikai Wang§ \\ University of Zurich
}

This version: February 14th, 2009

\begin{abstract}
We develop a theory of corporate liquidity demand, capturing the fact that a firm's borrowing capacity depends on news on future investment profitability. In our model, bad news on future investment profitability reduces a firm's borrowing capacity and therefore increases the need for internal finance. Consequently, the firm's cash savings respond negatively to news on future profitability. This negative correlation is strongly supported by our empirical evidence using a combined data set of Compustat and IBES. Moreover, both our simulation and empirical results show that the sensitivity of cash savings to news on future profitability is a reliable indicator of the presence of financial constraints at firm level.
\end{abstract}

JEL Classification: G3

Keywords: News, Financial Constraint, Corporate Savings

\footnotetext{
*We would like to thank Steve Bond and Kjetil Storesletten for helpful comments.

${ }^{\dagger}$ School of Economics and Finance, The University of Hong Kong. Phone: (+852) 28578506. Email: kaijic@hku.hk

${ }^{\ddagger}$ Department of Economics, Chinese University of Hong Kong. Phone: (+86) 2165643514. Email: zsong@fudan.edu.cn

§Institute for Empirical Research in Economics, University of Zurich, Zurich 8006, Switzerland. Phone: (+41) 76466 2487. Email: yikai.wang@iew.uzh.ch. Financial support from the Swiss National Science Foundation (SNF Grant "Appropriate Institutions in the Development Process", no. 100014-122636) is gratefully acknowledged.
} 


\section{Introduction}

Recent empirical studies have found that prospects in both future investment opportunities and future external borrowing capacity are two key factors in a firm's liquidity management. ${ }^{1}$ An ignored fact by this literature, however, is the rich interaction between these two factors. In particular, firms' external borrowing capacity may rely heavily on their business prospects, which are largely driven by news on future profitability. Examples of this relationship can be found in recent subprime-mortgage crisis: bad news on future profitability caused a tightening of credit by banks to many firms to prevent future default. Given the key roles of these two factors, taking into account their interaction may therefore provide new insights into firms' liquidity management. The impact of business prospects on borrowing capacity, moreover, suggests a unique way of identifying the presence of financial constraint at firm level, by observing how corporate savings respond to news on future profitability.

The purpose of this paper is therefore two folds: first, we develop a theory of corporate liquidity demand, capturing the dependence of firm's borrowing capacity on news about future investment profitability. ${ }^{2}$ Second, we wish to ask to what extent a firm's propensity to save cash out of news on future profitability (referred to as the "news sensitivity of cash") is a useful indicator of the presence of financial constraints at firm level.

Our key model ingredient is the presence of limited enforcement of debt repayment. This contractual friction limits a firm's external borrowing capacity to a fraction of future firm value. News on future profitability can thus have an immediate impact on the external borrowing capacity via firm value. Consequently, news not only affect the first best demand for capital and thus the demand for funds, but also the supply of external funds. The impact of news on cash savings, which serve to fill the gap between the financing need and external borrowing capacity, is therefore governed by the tension between the demand- and supply-side effects.

The major theoretical finding of this paper is that firms' cash savings respond negatively to news on future profitability in an economy calibrated to the U.S. data. This result is in sharp contrast to recent studies by Almeida, Campello and Weisbach (2004) and Riddick and

\footnotetext{
${ }^{1}$ See, for example, Almeida, Campello and Weisbash (2005) for evidence on corpoarte cash savings for financially constrained firms. Similar message was conveyed by Bates, Kahle and Stulz (2006), which find that between 1980 and 2004 firms with negative net income, which are more likely to be financially constrained, increased cash holdings much faster than firms with positive net incomes. These empirical findings reflect the fact that a major incentive for firms to hoard cash is to finance future investment in anticipation of future limited borrowing capacity.

${ }^{2}$ A tightening of credit standard may further worsen the prospects on firms' porfitability.
} 
Whited (2007), both of which find a positive response of cash savings to future investment opportunities. Our negative correlation hinges on the impact of news on firms' borrowing capacity. Good news on future profitability increase firm value and expand borrowing capacity, and hence reduce the need for internal finance. Since cash hoarding is costly, this encourages firms to reduce cash savings and reallocate resource to capital investment.

Our simulation results show that such negative correlation between news and cash savings is robust to a broad set of parameter values. By contrast, if shocks are on the current technology and thus the current cash flow, a common assumption in the literature, whether cash savings respond positively or negatively to such shocks (referred to as "the cash flow sensitivity of cash") turns out to be sensitive to different parameterization. ${ }^{3}$ These results suggest that the use of news sensitivity of cash may provide a more reliable test for financial constraints than cash flow sensitivity of cash.

We then proceed on an empirical level to test the key predictions of our model. To obtain proxy for expected firm values, we use a combined data set of Compustat and IBES and construct the expected firm value by discounting securities analysts' forecasts of future earnings. ${ }^{4}$ Our empirical results provide strong support for our theory. In particular, the estimated coefficient on expected firm value is significantly negative under first difference GMM panel regression. To test the role of news sensitivity of cash as an indicator of the presence of financial constraints, we partition the whole sample into two sub-samples with financially unconstrained and constrained firms in each alone. Five alternative approaches suggested by the literature are used for partition: asset size, employee size, payout policy, bond ratings, and commercial paper ratings. We find for each of the five schemes, news sensitivity of cash is negative and significantly different from zero for constrained firms, but not statistically different from zero for unconstrained firms. These findings show that news sensitivity of cash is a reliable indicator of the presence of financial constraints at firm level.

Our work is related to several strands of the literature. First, our model specification of the external borrowing constraint is closely related to Jermann and Quadrini (2006). There are two main differences, however. First, they shut down the use of liquid asset as a source of financing, which is the focus of our paper. Moreover, their paper is interested in the aggregate implications of financial constraints, while our purpose is to test directly their implications at firm level and find a useful indicator of the presence of financial constraints.

\footnotetext{
${ }^{3}$ The non-robustness of the effects of current cash flow (or cash flow effect) was first mentioned by Riddick and Whited (2007) and confirmed by our simulation result.

${ }^{4}$ Alternatively, one may use Tobin's $q$ based on stock market valuation as a proxy for expected firm value. However, for reasons that will be discussed below, we find that our measure of average $q$ dominates Tobin's $q$.
} 
Our paper also contributes to the literature on the effects of financial constraints on firm's behavior. Despite the recognition for the importance of financial constraints, the finance and macroeconomic literature has long debated over strategies to identify the presence of financing constraint at firm level. Our work departs from the existing studies in this literature along three aspects.

First, to our knowledge, this paper is the first to link firms' external borrowing capacity to news on future profitability. This leads us to conclude quite differently from previous theoretical and empirical results. In both Almeida, Campello and Weisbach (2004) and Riddick and Whited (2007), firms' borrowing capacity is either fixed or unrelated to future profitability. As a result, the response of cash savings to news is typically positive because good news cause only an increase in future financing need and, by assumption, have no impact on future supply of external funds.

Second, our work is among the first to formalize the impact of news shocks on corporate savings. Much attempt so far has been made to use the impact of cash flow shocks to identify the presence of financial constraints at firm level. ${ }^{5}$ This approach, however, has been questioned by many others on both theoretical and empirical ground. ${ }^{6}$ Our paper finds the robustness of news sensitivity of cash at both theoretical and empirical level. As a result, it provides an empirically reliable test of the presence of financial constraints.

Third, our empirical work, by using analysts earnings forecast data to construct expected firm values, provides a more precise measure of future profitability. Most studies use Tobin's $q$ based on stock market valuation to capture future investment opportunities. This strategy was challenged by Bond and Cummins (2001), which find that Tobin's $q$ constructed using market value is systematically biased and serial correlated. Another key finding of that paper is that using average $q$ constructed from analysts' earning forecast make the $Q$ investment model perform dramatically better. These findings motivate us to use analysts earning forecast data to construct expected firm values. Accordingly, our measure of firm value allows us to obtain a more precise estimate of the effect of news on corporate savings.

The paper is organized as follows: Section 2 introduces a theory of liquidity demand. In Section 3, we calibrate the model to U.S. data. Section 4 reports and discusses our numerical results. Section 5 presents the empirical tests of our model implications. Section 6 concludes.

\footnotetext{
${ }^{5}$ Beginning with Fazarri, Hubbard and Peterson (1998), researchers have explored the sensitivity of investment to cash flow to test for the presence of financial constraint. More recently, Almeida, Campello and Weisbach, (2004) argue that the effect of financial constraints can be caputured by the firm's propensitiy to save cash out of cash flow.

${ }^{6}$ For example, Kaplan and Zingales (1997) and Erickson and Whited (2000) questioned the robustness of cross-sectional patterns presented in Fazarri et. al (1988). Riddick and Whited (2007) show that the sign of cash flow effect is not robust to the persistence of shocks.
} 


\section{A Model of Liquidity Demand}

We consider a discrete time, infinite horizon partial equilibrium model. The model structure is kept as simple as possible to highlight how corporate savings respond to news on future profitability, which govern the tightness of future borrowing capacity.

A risk neutral firm uses capital and labor to produce output. The production technology is given by

$$
Y_{t}=A_{t}\left(K_{t}^{\alpha} H_{t}^{1-\alpha}\right)^{\gamma}
$$

where $K_{t}$ is the beginning-of-period capital, $H_{t}$ is the labor employed, and $A_{t}$ is the level of technology, which is stochastic. $\gamma \in(0,1)$, implying decreasing returns to scale for production. The assumption of decreasing returns indicates that the firm generates positive profit. Each period, working capital is required for production to be operative. ${ }^{7}$ The size of working capital required, denoted as $f\left(K_{t}, H_{t}\right)$, increases with the scale of production.

At each period, with probability $1-\phi$ the firm becomes unproductive. This variable is interpreted as the probability that the firm retains the ability to make profit.

\subsection{Firm Financing}

The working capital required at time $t$ can be financed from two channels: liquid asset accumulated at the end of period $t-1$, denoted as $L_{t}$, and external borrowing at the beginning of period from an outside lender. Clearly, if there is no cost to external finance, it is irrelevant whether to finance the firm from the internal or external funds, and there is no role for liquid asset.

To give a role for corporate liquidity, we introduce financial frictions to drive a wedge between the value of internal and external fund. We assume that the ability to borrow is bounded by the limited enforcement of the debt repayment à la Jermann and Quadrini (2006). At the end of the period, the firm has the ability to default the debt repayment. Appendix shows that the incentive-compatibility condition imposes the following financial constraint

$$
f\left(K_{t}, H_{t}\right)-L_{t} \leq \theta V_{t}=\theta E_{t}\left[\sum_{j=1}^{\infty}\left(\frac{\phi}{1+r}\right)^{j} D_{t+j}\right]
$$

where $V_{t}$ is the value of the firm at the end of period $t, r$ is the interest rate, and $D_{t+j}$ is the dividend at period $t+j$. Constraint (2) features the endogeneity of borrowing capacities: the

\footnotetext{
${ }^{7}$ According to Fazzari and Petersen (1993), for firms in fast growing industries, own-firm innovation and innovation spillovers generate new investment opportunities continuously. This creates a need for working capital to smooth investment.
} 
firm can borrow up to a fraction $\theta$ against its future value. News on future profitability can thus affect borrowing capacities via firm value. We parameterize $f\left(K_{t}, H_{t}\right)$ as follows:

$$
f\left(K_{t}, H_{t}\right)=\chi K_{t}+(1-\chi) H_{t}
$$

where $\chi$ denotes the fraction of working capital associated with the use of capital.

Finally, following the literature, we assume that a firm's dividend payout is subject to a quadratic adjustment cost. The total cost of payout, $D_{t}$, is

$$
\varphi\left(D_{t}\right)=D_{t}+\kappa\left(D_{t}-\bar{D}\right)^{2}
$$

where $\bar{D}$ represent the long run dividend payout level. In case of negative shocks to current cash flow or future investment opportunity, this adjustment cost also captures the possible costs associated with equity issuance, such as the underwriting fees and agency costs. ${ }^{8}$

\section{$2.2 \quad$ Firm's Problem}

To capture the interaction between borrowing capacity and firm behaviors, we specify the firm's problem in a stochastic dynamic framework. The only novel feature is our introduction of the financial constraint (2).

For analytical convenience, we write this problem recursively. The states of the firms are capital $K$ and liquid asset $L$, in addition to the exogenous states $s$ that we shall define later. Conditional on survival, the firm choose hours employed $H$, the dividend $D$, new capital $K^{\prime}$ and new liquid asset $L^{\prime}$, to maximize the value of expected future dividends. The Bellman equation for the problem is

$$
V(s ; K, L)=\max _{K^{\prime}, H^{\prime}, L^{\prime}, D}\left\{D+E\left[\frac{\phi}{1+r} V\left(s^{\prime} ; K^{\prime}, L^{\prime}\right)\right]\right\}
$$

subject to

$$
\begin{aligned}
\varphi(D) & =Y-w H-\left(K^{\prime}-(1-\delta) K\right)-\left(L^{\prime}-\left(1+r_{L}\right) L\right), \\
\chi K+(1-\chi) H-L & \leq \theta E\left[\frac{\phi}{1+r} V\left(s^{\prime} ; K^{\prime}, L^{\prime}\right)\right] .
\end{aligned}
$$

where $r_{L}$ is the rate of return for liquid asset. We assume that $1+r_{L}<\frac{1+r}{\phi}$, i.e., $r_{L}$ is strictly dominated by the interest rate adjusted by the firm survival rate. It is immediate from the above financial constraint that borrowing capacities and future firm value interact with each

\footnotetext{
${ }^{8}$ Notice that without the dividend issuance cost, the economy is essentially equivalent to a frictionless economy. In this case, the impact of future investment opportunity on firm's borrowing capacity can be costlessly accommodated through changes in firms' equity.
} 
other: the former varies in response to changes in the latter. Changes in borrowing capacity, in turn, affect the firm's future value via its impact on optimal decisions of investment and saving.

The first order conditions can be written as

$$
\begin{aligned}
(1+\theta \lambda) E\left[\frac{\phi}{1+r}\left(\frac{1+r_{L}}{\varphi^{\prime}\left(D^{\prime}\right)}+\lambda^{\prime}\right)\right] & =\frac{1}{\varphi^{\prime}(D)}, \\
(1+\theta \lambda) E\left[\frac{\phi}{1+r}\left(\frac{1+Y_{K^{\prime}}-\delta}{\varphi^{\prime}\left(D^{\prime}\right)}-\chi \lambda^{\prime}\right)\right] & =\frac{1}{\varphi^{\prime}(D)}, \\
\frac{Y_{H}-w}{\varphi^{\prime}(D)} & =\lambda(1-\chi),
\end{aligned}
$$

where $\lambda$ is the Lagrangian multiplier associated with the financial constraint, $Y_{X}$ denotes the partial derivative of $Y$ with respect to variable $X$.

The LHS of (7) represents the expected marginal return of next-period liquid assets $L^{\prime}$. The direct return of $L^{\prime}$, adjusted by dividend payout costs, is equal to $\left(1+r_{L}\right) / \varphi^{\prime}\left(D^{\prime}\right)$. Holding liquid assets rewards additional $\lambda^{\prime}$ via relaxing the next-period financial constraint. Moreover, the return of $\left(1+r_{L}\right) / \varphi^{\prime}\left(D^{\prime}\right)+\lambda^{\prime}$ is further amplified by the effect of $L^{\prime}$ on future firm value, which provides current liquidity worth of $\theta \lambda$. The RHS of (7) reflects the marginal cost of next-period liquid assets: increasing one-unit of $L^{\prime}$ crowds out dividend payout by $\varphi^{\prime}(D)$. Similarly, the LHS and RHS of (8) stand for the marginal returns and costs of next-period capital $K^{\prime}$, respectively.

Equation (9) shows that the marginal cost of the financial constraint, $\lambda$, is primarily determined by the wedge between the marginal labor productivity $Y_{H}$ and wage rate $w$. Intuitively, one can see from (2) that increasing liquid asset relaxes the financial constraint and allows the firm to hire more labor, which pushes the allocation towards the first-best.

To get some intuition for the role of liquid asset, let us consider the case in which the constraint (6) is not binding $\left(\lambda=\lambda^{\prime}=0\right)$. Then, the Euler equation (7) cannot hold as $1+r_{L}<$ $\frac{1+r}{\phi}$. In other words, it is optimal to accumulate no liquid asset for an unconstrained firm. Consequently, (8) and (9) reduce to the standard demand equations for capital and labor: $Y_{K^{\prime}}=\frac{1+r}{\phi}-1+\delta$ and $Y_{H}=w$.

Under binding financial constraint, ${ }^{9}$ it is easy to show the determinants of corporate savings

${ }^{9}$ At steady state, (7) becomes

$$
(1+\theta \bar{\lambda}) \frac{\phi}{1+r}\left(1+r_{L}+\bar{\lambda}\right)=1
$$

Steady-state values are marked by overbars. This solves $\bar{\lambda}$. Our assumption of $1+r_{L}<\frac{1+r}{\phi}$ ensures that $\bar{\lambda}>0$. Therefore, if $\chi \bar{K}+(1-\chi) \bar{H}<\theta \frac{\phi}{1+r} V(\bar{A} ; \bar{K}, \bar{L})$ holds, the financial constraint will be binding at steady state. 
by rearranging (6):

$$
L^{\prime}=\underbrace{\chi K^{\prime}+(1-\chi) H^{\prime}}_{\text {demand-side effect }}-\underbrace{\theta E\left[\frac{\phi}{1+r} V\left(A^{\prime \prime} ; K^{\prime \prime}, L^{\prime \prime}\right)\right]}_{\text {supply-side effect }} .
$$

(10) shows that the next-period liquid asset, or equivalently corporate savings today $\left(L^{\prime}-L\right)$, is governed by the tension between next-period working capital and the end-of-next-period firm value. For instance, future investment opportunities may increase demand for future capital and labor and thus require a larger size of working capital. This financing need encourages more liquid assets to be accumulated today. We refer to this effect on liquid assets as the demand-side effect. On the other hand, future investment opportunities also increase future firm value and expand future borrowing capacity, supplying more liquidity that can be used to substitute for liquid assets. This is referred to as the supply-side effect.

\section{Calibration}

To obtain a quantitative assessment of the model, we calibrate the economy to the annual U.S. data. We set $\gamma$ to 0.85, the value used by Atkeson and Kehoe (2001). The parameter $\alpha$ is then set so that the labor income share is 0.6 . This yields a value of $\alpha$ of 0.294 . The depreciation rate $\delta$ is set to match an investment capital ratio of 0.074 , the average between 1960 and 2004. The interest rate, $r$ is set to $4 \%$. We let the firm survival probability $\phi$ be 0.90, which is broadly consistent with the U.S. data for the manufacturing and business service sector reported by OECD (2001).

We set $r_{L}=0$ for normalization. We choose the value of $\theta$ so that the ratio of liquid asset to the sum of liquid and physical asset for the firm at the steady state matches the average ratio of cash to total assets for a financially constrained firm in our sample of Compustat data. As will be explained in more detailed in the empirical part, one of our identification schemes for a financially constrained firm is that if a firm does not have a commercial paper rating during our sample period (1971-2005), it is classified as financially constrained. Otherwise, it is considered as a unconstrained firm. Under this scheme, the average ratio of cash to total asset for constrained firms between 1971 and 2005 is $12.4 \%$. This gives $\theta=0.31$.

We calibrate the value for $\chi$ such that about half of the working capital is associated with the use of capital and half with the use of labor. ${ }^{10}$ The value of $w$ is chosen to target a level of labor input of 0.33 at steady state. ${ }^{11}$

\footnotetext{
${ }^{10}$ We show later in this paper that our qualitative result regarding the impact of news on cash savings is robust to any $\chi \in[0,1)$.

${ }^{11}$ Varying $w$ does not change significantly our qualitative results regarding the impact of news on cash savings.
} 
We specify the stochastic process for $A$ under two cases in order to understand the impact of different shocks on corporate savings via the dynamic interaction between future borrowing capacity and firm value.

- Case 1: News Shocks on Future Technology:

$$
\log A_{t+1}=\rho \log A_{t}+\epsilon_{t}^{F}
$$

where $\epsilon_{t}^{F}$ denotes innovations regarding information on the next period.

- Case 2: Shocks on Current Technology:

$$
\log A_{t}=\rho \log A_{t-1}+\epsilon_{t}^{C}
$$

In this process, $\epsilon_{t}^{C}$ affects the current technology $A_{t}$.

Note that the process (11) is different from the standard AR(1) specification in (12): new information on $A_{t+1}$ arrives at time $t$, before it is realized. As a result, next period productivity is perfectly predictable. In this case, the exogenous state variable $s=\left(A, A^{\prime}\right)$. By contrast, in the $\mathrm{AR}(1)$ case, a specification widely adopted by the literature, shocks are on the current level of technology. Accordingly, the exogenous state variable $s=A$. Since news shocks $\epsilon_{t}^{F}$ affect $A_{t+1}$ directly, specification (11) allows us to isolate the impact of changes in prospect of future investment opportunity from changes in current technology. Different from news shocks, $\epsilon_{t}^{C}$, also called cash flow shock, highlights the impact of a change in the current technology, which has a first-order effect on current cash flow. Comparing responses of corporate saving to the above two types of shocks, therefore, helps distinguish a firm's propensity to save cash out of news (news sensitivity of cash), which is the focus of this paper, from its propensity to save cash out of changes in current cash flows (cash flow sensitivity of cash).

Following Hennessy and Whited (2007), we set the serial correlation coefficient for shocks on current technology $\rho=0.66$ and the associated standard deviation of the shock $\sigma_{\epsilon}$ is set at 0.121. To compare the effects of these two types of shocks, we set the two parameter values for news shocks to be the same as their counterparts for shocks on current technology. We shall provide robustness check of our results to $\rho$ later in this paper.

Table 1 summarizes the parameter values for this economy. 
Table 1. Parameter Values

\begin{tabular}{clc}
\hline \hline Symbol & \multicolumn{1}{c}{ Definition } & Value \\
$\alpha$ & Capital share in production function & 0.36 \\
$\phi$ & Entrepreneurial survival rate & 0.90 \\
$\gamma$ & Decreasing return to scale & 0.85 \\
$\delta$ & Depreciation rate for capital & 0.07 \\
$\rho$ & Autocorrelation coefficient & 0.66 \\
$\sigma_{\epsilon}$ & Standard deviation of information innovation & 0.121 \\
$r$ & Interest rate & 0.04 \\
$\theta$ & Default parameter & 0.31 \\
$\chi$ & Share of working capital associated with $K$ & 0.43 \\
$w$ & Wage rate & 0.70 \\
$r_{L}$ & Rate of return for liquid asset & 0.0 \\
\hline
\end{tabular}

\section{Numerical Results}

In this section, we present the impulse responses of corporate liquidity under two types of shocks: news shocks on future profitability and cash flow shocks due to unanticipated technology fluctuation.

\subsection{News shock on Future Technology}

To examine how the economy reacts to news about future profitability, we consider the following experiment: at period 0 , the economy is at steady state. At the beginning of period 1 , all agents receive unanticipated news that the technology $A$ will increase by one percent at period 2 . At the beginning of period 2 , the technology improvement is materialized.

\section{[Insert Figure 1]}

Panel A of Figure 1 depicts the response of corporate liquidity to good news that arrive in period 1. We see that the firm reduces cash holdings at the end of period 1 , or in other words corporate saving declines. The underlying mechanism for dissaving in response to good news about future technology can be seen from Panel B to D, which show the response of capital, labor and end-of-period firm value, respectively. Not surprisingly, the improvement of future technology gives rise to future investment opportunity. This generates two effects. On the one hand, the demand-side effect in the RHS of (10) asks for more liquid assets to be accumulated in order to finance a larger size of working capital. On the other, good news also increases firm value and external borrowing capacity, which then works through the supply-side effect in the RHS of (10) to reduce the demand for liquid asset. Interestingly, the supply-side 
effect turns out to be quantitatively larger than the demand-side effect, since there is a selfenhancing mechanism for the determination of borrowing capacity: the technological shift increases borrowing capacity by affecting firm value. The larger borrowing capacity, in turn, allows the firm to deploy more capital and labor. The feedback thus increases firm value and borrowing capacity even further.

It is noteworthy that our result regarding the response of cash saving to news is opposite to Almeida, Campello and Weisbach (2004) and Riddick and Whited (2007). In their models the tightness of the financial constraint is unrelated to prospects of future profitability. This shuts down the above-mentioned supply side effect of news shocks. As a result, the response of cash savings to news is typically positive.

To help understand the resource reallocation following the news shock, we present the response of dividend payout in Panel E. Along with a decline in corporate liquidity, dividend payout increases slightly at period 1 . This suggests that the increase in physical capital investment in response to the good news comes solely from a reallocation of internal funds from liquidity asset to physical capital.

Panel $\mathrm{F}$ shows that cash flows also increase on impact in response to the good news. ${ }^{12}$ This increase in cash flow arises from an endogenous increase in the labor deployed at period 1 due to the relaxed financial constraint, as Panel C indicates. Note that under news shocks, corporate cash flows and corporate liquidity move in the opposite direction. However, as will be shown below, it is not correct to simply argue that when cash flows increase, corporate saving must decrease.

\subsection{Shocks on Current Technology}

We now examine the response of corporate saving to shocks on current technology. We consider the following experiment: at period 0 , the economy is at steady state. At the beginning of period 1 , there is a one-percentage increase to $A$ unanticipatedly. Starting from period $2, A$ falls back to the steady state according to (12).

\section{[Insert Figure 2]}

Panel A of Figure 2 depicts the response of liquid assets to current technological shock. We see that the firm chooses to accumulate more liquid assets when the shock to current technology arrives. The underlying mechanism for the increase of corporate saving can be seen from Panel B to D, which show how capital and labor response to the current technological shock,

\footnotetext{
${ }^{12}$ Cash flow equals firm revenue minus wage.
} 
respectively. The improvement of the current technology increases capital, labor and end-ofperiod firm value, due to its persistent impact on future technology. ${ }^{13}$ Like news shocks, this generates both demand-side effect and supply-side effect as in (10). Quantitatively, however, the supply-side effect is much smaller under shocks to current technology. This is primarily due to the fact that the impact of the current technological shock on future firm value and future borrowing capacity is much weaker than that of the news shock, as can be seen by comparing the magnitude of the increase in firm value at the end of period 2 between Panel D of Figure 1 and 2.

Our positive cash flow sensitivity of cash is opposite to the results in Riddick and Whited (2007). In their model, which adopted the same persistence for cash flow shocks as ours, cash flow shocks generate a negative response of cash savings on impact. The key reason for this disparity lies in the difference of cost of external finances between these two papers: in our model the presence of financial constraints implies cost of external finance is extremely high beyond some upper bound, while in their model the cost of external finance shows up as a combination of fixed and linear-quadratic cost for equity issuance.

Comparing Panel F in Figure 1 and 2, we see that the correlation between corporate saving and cash flow depends on different types of shocks. What helps us to identify these two types of shocks is that shocks to current technology has a first order impact on the cash flow at period 1, while the corresponding magnitude of the effect of news shock is only of second order. The opposite is true for the relative magnitude of the impacts of these two shocks on future firm values. This quantitative difference allows us to identify the partial effects of news on future profitability and changes in current cash flows on corporate liquidity demand in our empirical exercise.

\subsection{Robustness Check}

We have shown that in our calibrated models, the firm reduces liquid assets in response to positive news shock, while liquidity increases in response to positive shocks on the current technology. In this subsection, we check the robustness of the above results for different parameterization. This work provides theoretical ground to answer the question that to what extent news sensitivity of cash (as opposed to cash flow sensitivity of cash) is a reliable indicator of the presence of financial constraints.

We consider our robustness to the following four parameters: the persistency of shocks $\rho$, the payout adjustment cost coefficient $\kappa$, the degree of decreasing returns to scale $\gamma$ and the

\footnotetext{
${ }^{13}$ Consistent with an increase in both liquid asset accumulation and physical capital investment, dividend payout drops drastically at period 1, as illustrated in Panel E.
} 
coefficient $\chi$ in (3). The results are presented in Figure 3.

\section{[Insert Figure 3]}

It can directly be seen from Figure 3 that the decline of liquid assets in response to good news is robust to different parameterization, except for very low persistency of technological shifts $(\rho<0.15)$. In an extreme case where $\rho=0$, the technological improvement at period 2 has no effect on technology afterwards and thus cannot directly affect firm value at the end of period 2. Consequently, the supply-side effect becomes very small and dominated by the demand-side effect.

In sharp contrast, the response of liquid assets to shocks on current technology turns out to be sensitive to different parameterization, except for the dividend payout adjustment cost coefficient $\kappa$. In particular, for sufficiently persistent shocks $(\rho>0.70)$, the technological improvement at period 1 has a quantitatively sizable effect on firm value at the end of period 2. This gives rise to a large supply-side effect, which dominates the demand-side effect and leads to a decrease of liquid asset. Also, for sufficiently small degree of decreasing return to scale $(\gamma>0.93)$ or sufficiently large $\chi(\chi>0.5)$, the response of cash to cash flow shocks turn out to be negative, indicating the dominance of the supply-side effect.

Overall, the results of our robustness check indicate a sharp prediction on the impact of news on corporate liquidity demand for financially constrained firms. This allows us to test our model and the usefulness of news sensitivity of cash to measure financial constraints using empirical data. Meanwhile, the non-robustness of the impact of cash flows shocks cast doubt on the empirical reliability of cash flow sensitivity of cash as a useful indicator of the presence of financial constraints at firm level.

\section{Empirical Test}

Our theory generates the following testable implications. Financially constrained firms should decrease their stock of liquid assets in response to good news on future profitability. By contrast, for unconstrained firms the estimate of news sensitivity of cash should not be statistically different from zero. Finally, the sign of cash flow sensitivity of cash is ambiguous. We now test our model's main predictions about news and cash flow sensitivities of cash and their predictability about financial constraints. 


\subsection{Measuring News and Cash Flow Sensitivities of Cash}

Ideally, we need news shocks and cash flow shocks as devices to identify news and cash flow sensitivities of cash. Though direct measures of these two types of shocks are not easy to be found, we can proxy these two shocks by cash flow and expectations on future profitability. In our model, both shocks affect current cash flow and expected future firm value. However, as we mentioned above, the quantitative effect of these two shocks on current cash flow and expected future firm value are very different. As a result, we can use variables of cash flow and expected future profits to capture cash flow shocks and news shocks. This implies that, for the group of financially constrained firms, we expect to see a negative estimated coefficient on expected firm value, while for the group of unconstrained firms the estimated coefficients should be statistically insignificant.

\subsection{The Empirical Model}

Our estimation equation is:

$$
C H_{i, t}=b_{1} C H_{i, t-1}+b_{2} C F_{i, t}+b_{3} Q_{i, t}+a_{i}+a_{t}+\varepsilon_{i, t} .
$$

$C H_{i, t}$ is the cash holding level for firm $i$ at the end of period $t, C F_{i, t}$ is the cash flow of firm $i$ in period $t$, and $Q_{i, t}$ is the discounted sum of expected profits for firm $i$ since period $t$. $a_{i}$ and $a_{t}$ denote firm and year effects, respectively. Three remarks on our empirical strategy are in order.

First, the use of the discounted sum of expected profits as a proxy for expected firm value deserves some discussion. In the literature, Tobin's $q$ is widely adopted to proxy expected firm value or future investment opportunity. However, as Bond and Cummins (2001) argued, there is a potential severe problem in Tobin's $q$ as a proxy of firm value due to deviations between stock market and fundamental values. If the deviations are pure random noises, there are available moments conditions like in Riddick and Whited (2007) or instruments like lagged financial variables to get unbiased estimates. But if the deviations are persistent and dependent on new information about firm fundamental value, all financial variables related to the fundamental value would be correlated with the deviations. As a result, no moment conditions are available to correct the bias. This motivate us to use the direct measure of expected firm value constructed from securities analysts' earnings forecasts, as suggested by Cummins, Hassett and Oliner (1999), Bond and Cummins (2001).

Second, like Tobin's $q$, our measure of expected firm value is also likely to suffer from measurement error problem. Therefore, we apply first difference GMM, using lagged financial 
variables as instrumental variables to get unbiased estimates.

Another important feature of (13) is that we introduce a $\operatorname{AR}(1)$ specification to describe the decision of cash holding. This is compatible with our theoretical framework. As a state variable in the model, cash available at the beginning of each period is an important factor for the determination of corporate saving. Moreover, many studies find that financially constrained firms associated with higher $Q$ tend to hold more cash, implying a positive relationship between cash holding and financial variables like $Q$ across firms. The corresponding non-availability of moment conditions casts doubt on the validity of leaving lagged cash in the error term.

\subsection{Data}

Our data set is a panel of combined Compustat and IBES firms. This is because Compustat data set provides firm's financial variables like cash flow, and IBES provides essential variables to construct expected firm profits. We also do the following adjustment to our sample. First, all financial variables are CPI adjusted into 1971 dollar. Second, following Almeida et. al. (2004), Riddick and Whited (2007), we exclude all firms with SIC classification between 4900 and 4999, between 6000 and 6999, or greater than 9000 .

We define variables as follows: booked asset is item 6; cash holding is item 1; cash flow is item $14+$ item 18; expected profits are constructed using expected first year profit, second year profit and long term growth rate from analysts. All variables are denominated by booked asset at the beginning of the year. Observations are dropped if cash holding, cash flow or $Q$ is missing. In addition, observations with negative asset or $Q$ are also dropped. Finally, we drop outliers by truncating the 1st and 99th percentage for cash holding, cash flow and $Q$.

The summary statistics of regression variables are reported in Table 2.

Table 2 Summary Statistics of Regression Variables

\begin{tabular}{lllll}
\hline \hline Variable & Mean & Median & Std. Dev. & N. Obs \\
\hline Cash Holding & .112 & .056 & .136 & 23305 \\
Cash Flow & .113 & .111 & .072 & 23305 \\
$Q$ & 1.331 & 1.210 & .525 & 23305 \\
\hline
\end{tabular}

\subsection{Financial Constraints Criteria}

In order to support our model implication that firms' cash policy should be different between financial constrained and unconstrained firm groups, we use five schemes to partition the sample into two sub-samples, according to firms' asset, employee, bond rating, commercial paper rating and pay out ratio, which are widely adopted by the literature. Following Bond 
et. al. (2004), each firm is marked as in one group in all its sample years. ${ }^{14}$

- Scheme 1 - asset: Small firms are more likely to be financially constrained. If a firm's asset is smaller than the median asset of all firms in the first year of the firm entering our sample, we classify the firm as a small firm, thus financially constrained. Other firms are unconstrained. This scheme is also used in Bond et. al. (2004).

- Scheme 2 - employee: Number of employees can also be used as a criteria for firm size. So we use number of employee to classify firms in the same way as in scheme 1 .

- Scheme 3 - pay out ratio: The payout ratio is the ratio of total distributions to operating income. Because financially constrained firms are likely to pay less dividend, we use it to classify groups by a similar way as in scheme 1 and 2: if the pay out ratio of a firm is lower than the median of the first year of the firm entering our sample, we regard it as financially constrained.

- Scheme 4 - bond rating: This variable reflects market assessment of a firm's credit quality. If a firm has never had a bond rating during our sample period, it may find it difficult to obtain external finance. Thus we classify it as financially constrained. A firm has ever had bond rating are counted as unconstrained.

- Scheme 5 - commercial paper rating: This is also a variable reflecting market assessment of credit quality. We use it as an alternative measurement of financial constraints. The way of firm classification is the same as in scheme 4 .

Table 3 presents summary statistics of cash holdings in our sample of financially constrained and unconstrained firms. Consistent with Almeida et al. (2004), our sample also shows that constrained firms hold far more cash than unconstrained ones.

\footnotetext{
${ }^{14}$ This is because in first-difference GMM, we can not sort different year observations of one firm into different groups.
} 
Table 3. Summary Statistics of Cash Holdings

\begin{tabular}{lcccc}
\hline \hline Cash Holdings & Mean & Median & Std. Dev & Obs. \\
\hline $\begin{array}{l}\text { Financial Constraint Criteria } \\
\text { 1. Firm asset }\end{array}$ & & & & \\
Constrained firms & 0.137 & 0.075 & 0.154 & 13850 \\
unconstrained firms & 0.074 & 0.040 & 0.090 & 9455 \\
$\begin{array}{l}\text { 2. Firm employee number } \\
\text { Constrained firms }\end{array}$ & 0.136 & 0.071 & 0.155 & 13668 \\
unconstrained firms & 0.077 & 0.042 & 0.090 & 9174 \\
$\begin{array}{l}\text { 3. Payout ratio } \\
\text { Constrained firms }\end{array}$ & 0.129 & 0.066 & 0.150 & 14710 \\
unconstrained firms & 0.082 & 0.045 & 0.100 & 8569 \\
$\begin{array}{l}\text { 4. Bond ratings } \\
\text { Constrained firms }\end{array}$ & 0.150 & 0.087 & 0.161 & 10230 \\
unconstrained firms & 0.082 & 0.044 & 0.102 & 13075 \\
5. Comm. paper ratings & & & & \\
Constrained firms & 0.128 & 0.067 & 0.148 & 16881 \\
unconstrained firms & 0.071 & 0.040 & 0.084 & 6424 \\
\hline
\end{tabular}

\subsection{Results}

Table 4 reports the estimation results for the whole sample. In addition to first-difference GMM, we also report results from pooled OLS (the first column) and within group estimation (the second) for comparisons. Following Bond and Cummins (2001), we use 3- and 4- year lagged $C H$ and $C F$ as instrumental variables in first difference GMM. The third column reports the estimated results. One can see that the specification passes the Hansen test, suggesting the validity of the lagged variables as instruments. ${ }^{15}$

The main finding from Table 4 is that the key coefficient of interest, $b_{3}$, turns out to be significantly negative in all specifications. Aside from the qualitatively robust feature of $b_{3}$, some quantitative differences across specifications are worth being mentioned. First, the smaller absolute values of $b_{3}$ in the first and second column are consistent with the previous finding of a positive correlation between $Q$ and $C H$, which tends to bias the coefficient of $Q$ upwards. Second, the estimated coefficient of $\mathrm{CH}_{t-1}$ in the first column is much larger than the one from within group and first difference GMM estimation. This is not surprising, as pooled OLS does not control firm specific effects. The lowest estimated coefficient of $\mathrm{CH}_{t-1}$ in the second column shows the downward bias problem when using within group estimation for dynamic panel models.

\footnotetext{
${ }^{15}$ The first-differenced errors are second-order correlated, implying that cash policy may also be influenced by variables other than $Q$ and $C F$. Fortunately, this will not bias the estimated coefficients of $Q$ and $C F$, which we are interested in, since our instruments are not correlated with error terms.
} 
Table 4. Alternative Estimates of Corporate Propensity to Save

\begin{tabular}{lccc}
\hline \hline & OLS & FE & GMM \\
\hline$C H_{t-1}$ & $.850^{* * *}$ & $.474^{* * *}$ & $.636^{* * *}$ \\
& $(.005)$ & $(.010)$ & $(.048)$ \\
$C F_{t}$ & $.143^{* * *}$ & $.277^{* * *}$ & $.263^{*}$ \\
& $(.009)$ & $(.013)$ & $(.140)$ \\
$Q_{t}$ & $-.005^{* * *}$ & $-.013^{* * *}$ & $-.036^{* *}$ \\
& $(.001)$ & $(.002)$ & $(.017)$ \\
$m 1$ & - & - & -12.88 \\
$m 2$ & - & - & 3.72 \\
Hansen & - & - & 0.777 \\
Obs. & 20086 & 20086 & 17239 \\
\hline
\end{tabular}

Note: $* * *, * *$ and $*$ is significant at $1 \%, 5 \%$ and $10 \%$, respectively. Standard deviations are in brackets. OLS, FE and GMM stands for pooled OLS, within group estimation and first difference GMM, respectively. $m 1$ and $m 2$ are tests for first and second order serial correlation for first-differenced residuals, respectively.

We next divide firms into constrained and unconstrained groups according to the five schemes, and run first difference GMM for each group sample. The results are presented in Table 5 . 
Table 5. Regression on Two Groups

\begin{tabular}{lcccccccccc}
\hline \hline & \multicolumn{2}{c}{1 1: Asset } & \multicolumn{2}{c}{ 2: Employee } & \multicolumn{3}{c}{ 3: Payout Ratio } & \multicolumn{2}{c}{ 4: Bond Rating } & \multicolumn{2}{c}{ 5: CP Rating } \\
& con. & uncon. & con. & uncon. & con. & uncon. & con. & uncon. & con. & uncon. \\
\hline$C H_{t-1}$ & $.629^{* * *}$ & $.526^{* * *}$ & $.602^{* * *}$ & $.562^{* * *}$ & $.645^{* * *}$ & $.404^{* * *}$ & $.616^{* * *}$ & $.590^{* * *}$ & $.559^{* * *}$ & $.522^{* * *}$ \\
& $(.057)$ & $(.068)$ & $(.061)$ & $(.071)$ & $(.056)$ & $(.075)$ & $(.058)$ & $(.065)$ & $(.064)$ & $(.063)$ \\
$C F_{t}$ & $.358^{* * *}$ & .030 & $.384^{* * *}$ & .096 & $.340^{* * *}$ & .137 & $.260^{*}$ & $.307^{* *}$ & $.412^{* * *}$ & .211 \\
& $. .117)$ & $(.157)$ & $(.126)$ & $(.178)$ & $(.129)$ & $(.130)$ & $(.154)$ & $(.134)$ & $(.100)$ & $(.178)$ \\
$Q_{t}$ & $-.039^{* *}$ & .012 & $-.049^{* * *}$ & -.020 & $-.043^{* *}$ & -.007 & $-.041^{* *}$ & .002 & $-.048^{* *}$ & -.019 \\
& $(.017)$ & $(.017)$ & $(.017)$ & $(.023)$ & $(.019)$ & $(.019)$ & $(.021)$ & $(.020)$ & $(.020)$ & $(.018)$ \\
$m 1$ & -11.04 & -8.06 & -10.36 & -7.95 & -11.34 & -5.80 & -10.61 & -8.41 & -9.15 & -8.70 \\
$m 2$ & 3.34 & 1.09 & 2.84 & 2.51 & 3.54 & 0.79 & 2.79 & 2.80 & 2.19 & 2.64 \\
Hansen & 0.847 & 0.377 & 0.771 & 0.491 & 0.799 & 0.123 & 0.660 & 0.361 & 0.813 & 0.570 \\
Obs. & 9772 & 7467 & 9613 & 7626 & 11882 & 5357 & 10259 & 6980 & 7028 & 10211 \\
\hline
\end{tabular}

Note: $* * *, * *$ and $*$ is significant at $1 \%, 5 \%$ and $10 \%$, respectively. Standard deviations are in brackets. "con" and "uncon" refers to constrained and unconstrained group, respectively. $m 1$ and $m 2$ are tests for first and second order serial correlation for first-differenced residuals, respectively.

We see that for each of the five schemes, news sensitivity of cash, reflected by the coefficient of $Q$, is negative and significantly different from zero for constrained firms. By contrast, it is not significantly different from zero for unconstrained firms. Also, although most schemes show a positive relation between cash holdings and cash flows for constrained firms, we see that cash flow sensitivity of cash is larger for unconstrained than constrained firms, if bond rate is used as the identification scheme. Therefore we conclude that news sensitivity of cash is an empirically more reliable indicator of the presence of financial constraints than cash flow sensitivity of cash.

These estimated results are in sharp contrast to positive coefficients of firm value found by Almeida, Campello and Weisbach (2004) and Riddick and Whited (2007). The difference is primarily because firm specific effects and lagged cash holdings are omitted in these two studies, which therefore tend to bias the coefficient of $Q$ upward.

To conclude, we find that financially constrained firms reduce cash holding when good news on future profitability arrive, while such news has no effect on cash policy of unconstrained firms. In addition, the effect of cash flow on cash policy is ambiguous. All these findings are consistent with our theoretical predictions on the news and cash flow sensitivities of cash. 


\section{Conclusion}

We develop a theory of corporate liquidity demand, capturing the fact that firms' external borrowing capacity depends on news on future investment opportunities. The incorporation of the impact of news on borrowing capacity leads us to conclude quite differently from previous theoretical and empirical results. In particular, we find that cash savings respond negatively to news on future profitability. This negative response occurs because good news on future profitability expand the external borrowing capacity and therefore provide additional resource for financing. The increase in the supply of external funds dominates the increase in the firstbest demand for investment, causing a decline in the demand for internal finance. By contrast, in early studies where firms' borrowing capacity is fixed or unrelated to news, the response of cash savings to news is typically positive, because good news cause only an increase in future financing need.

We find strong empirical support for the negative impact of news on cash holdings, using a combined data set of Compustat and IBES. Furthermore, this negative impact is only significant for financially constrained firms under each of the five schemes suggested by the literature to classify firms into constrained and unconstrained one. Therefore, we conclude that news sensitivity of cash is an empirically reliable indicator of the presence of financial constraints at firm level.

\section{Appendix}

In this section, we derive the financial constraint (2). Assume production at each period requires an amount of working capital, denoted as $f_{t}=f\left(K_{t}, H_{t}\right)$, with both $f_{1}$ and $f_{2}$ strictly positive, where $f_{x}$ is the partial derivative of $f$ with respect to the $x$-th argument. Working capital is used at the beginning of time $t$ and are recovered at the end of time $t$, after all transactions have been completed. At the beginning of each period, The firm borrows the financing gap between the working capital required $f_{t}$ and its internal fund, $L_{t}$, from the outside lender. At the end of each period, debt is repaid back. Because this is a intra-period loan, the net interest payment is zero.

The firm has the ability to default the debt repayment. ${ }^{16}$ Upon default, the lender can take over the firm and recover a fraction $\mu$ of the end-of-period firm value, denoted as $V_{t}$, which is the simply the present discount value of the expected dividend payout from tomorrow on. Here

\footnotetext{
${ }^{16}$ Similarly, Hart and Moore (1998) assume that beyond the project cost, a fraction of the loan that the debtor receives from the creditor represents the nonrecourse financing, which is not seizable by the creditor.
} 
the underlying assumption is that only the firm has the required talent to produce efficiently. Denote by $\omega$ the bargaining power of the firm and $1-\omega$ the bargaining power of the lender. Bargaining is over the repayment of the debt, denoted as $\widehat{f}_{t}$. If they reach an agreement, the entrepreneur gets $\left(f_{t}-L_{t}\right)-\widehat{f}_{t}+V_{t}$, and the lender gets $\widehat{f}_{t}$, If there is no agreement, the firm gets $f_{t}-L_{t}$ and the lender gets $\mu V_{t}$. Therefore, the net value for the firm to reach an agreement is $V_{t}-\widehat{f}_{t}$ and the net value for lender is $\widehat{f_{t}}-\mu V_{t}$. The bargaining problem solves:

$$
\max _{\widehat{f_{t}}}\left\{\left(V_{t}-\widehat{f_{t}}\right)^{\omega}\left(\widehat{f}_{t}-\mu V_{t}\right)^{1-\omega}\right\}
$$

Taking the first order condition, we get $\widehat{f}_{t}=[1-\omega(1-\mu)] V_{t}$. Incentive compatibility requires that for the firm the value of nondefault, $V_{t}$, should be no less than the value of default, that is $\left(f_{t}-L_{t}\right)-\widehat{f}_{t}+V_{t}$. Hence we have

$$
[1-\omega(1-\mu)] V_{t} \geq f_{t}-L_{t}
$$

Denote $[1-\omega(1-\mu)]$ as $\theta$. Then we get $(2)$ in our model. 


\section{References}

[1] Atkeson A. and P. Kehoe (2001), "The Transition to a New Economy after the second Industrial Revolution," Minneapolis Fed Working Paper \#606

[2] Almeida, H., M. Campello and M. Weisbach (2004), "The Cash Flow Sensitivity of Cash", Journal of Finance, 4, 1777-1804

[3] Bates, T., K. Kahle and R. Stulz (2007), "Why Do U.S. Firms Hold So Much More cash than They Used To?" NBER working paper, w12534

[4] Bond, S. and J. Cummins (2001), "Noisy Share Prices and the Q Model of Investment", IFS Working Papers, W01/22

[5] Bond, S., A. Klemm, R. Newton-Smith, M. Syed and Gertjan Vlieghe (2004), "The Roles of Expected Profitability, Tobin's Q and Cash Flow in Econometric Models of Company Investment", IFS Working Papers, W04/12

[6] Cummins, J., K. Hassett, and S. Oliner (2006), "Investment behavior, Observable Expectations and Internal Funds," American Economic Review, 96(3), 796-810

[7] Erickson, T. and T.M. Whited (2000), "Measurement Error and the Relationshipbetween investment and Q", Journal of Political Economy, 108, 1027-1057

[8] Fazarri, S. G. Hubbard and B. Petersen (1988), "Financing Constraints and Corporate Investment", Brooking Papers on Economic Activity,1 141-195

[9] Fazzari, S. and B. Petersen (1993), "Working Capital and Fixed Investment: New Evidence on Financing Constraint," RAND Journal of Economics, 24, 328-342

[10] Hart, O. and J. Moore (1998), "Default and Renegotiation: A Dynamic Model of Debt," Quarterly Journal of Economics, 1-41

[11] Hennessy, C. and T. Whited (2007), "How Costly is External Financing? Evidence from a Structual Estimation", Journal of Finance, 62, 1705-1745

[12] Jermann, U. and V. Quadrini (2006b), "Financial Innovations and Macroeconomic Volatility," NBER working paper, 12308

[13] Kaplan, S., and L. Zingales (1997), "Do Investment-cash Flow Sensitivities Provide Useful Measures of Financial Constraints?," Quarterly Journal of Economics, 112, 169-215 
[14] OECD (2001), "Productivity and Firm Dynamics: Evidence from Microdata," Economic Outlook, 69(1), 209-223

[15] Opler, T., L. Pinkowitz, R. Stulz and R. Williamson (1999), "The Determinants and Implications of Corporate Cash Holdings," Journal of Financial Economics, 52, 3-46

[16] Riddick, L. and T. Whited (2007), "The Corporate Propensity to Save", forthcoming, Journal of Finance 